\title{
SCREENING OF PREGNANT WOMEN FOR PRESENCE OF IGG ANTIBODIES FOR RUBELLA, MUMPS, MEASLES AND VARICELLA VIRUSES IN TERTIARY CARE HOSPITAL , JAIPUR
}

\section{Dr. Seema Malav}

\section{Dr. Bharti Malhotra*}

\section{${ }^{*}$ Corresponding Author}

\section{ABSTRACT}

Background : The aim of this study were assess the susceptible pregnant women for vaccine preventable infection like rubella, mumps, measles and varicella viruses. Infection of mothers with these viruses during pregnancy can be serious. They can cause congenital infections, miscarriage, stillbirth and death of fetuses. Material and Method : This study is cross sectional. To determine the presence of IgG antibodies for rubella, mumps, measles and varicella viruses, blood samples were collected, stored at -700 c. Serum was separated for detection of IgG antibodies for these viruses by using enzyme linked immunosorbant assay.

Results : Of 277 samples evaluated for IgG antibodies. Susceptibility Of pregnant women for rubella, mumps measles and varicella viruses were $7.6 \%, 17.6 \%, 7.2 \%$ and $19.5 \%$ respectively. Susceptibility rates for rubella and mumps were higher in rural population as compares to urban while for varicella urban population was more susceptible, but it was not statistically significant. No correlation could be observed in susceptibility to different to different viruses and their education status and age of patients, but youngest age group was most susceptible to varicella and oldest group to rubella. Primigravida were more susceptible to rubella and varicella while multigravida were more susceptible to mumps and measles.

Conclusion : Majority of the pregnant women had protective levels of IgG antibody although susceptibility to rubella, mumps measles and varicella were low. Intensification of MMRV immunization of all females of child-bearing age is advocated.

KEYWORDS : Rubella, Mumps, Measles, Varicella, IgG antibodies, Pregnant women, Immunization.

\section{INTRODUCTION}

Women are at an increased risk of acquiring certain transmissible diseases during pregnancy due to transient immunosuppression ${ }^{(1)}$. This may be enhanced due to missing vaccination, decreased uptake of the vaccine, reinfection of mothers and immigration from places where these viruses are endemic ${ }^{(2)}$. These infections can transmit to neonate transplacentally, perinatally or postnatally. The term congenital infection is used if the vertically transmitted infection persists after childbirth.Vertically transmitted infections are caused by various bacteria, viruses and parasites.

Many vertically transmitted viral infections have no effective treatment but some notably rubella, mumps, measles and varicella can be prevented by vaccinating the mother prior to pregnancy.

Rubella virus belongs to family Togaviridae and genus Rubivirus. Rubella causes maculopapular rash with fever in children which can occasionally infect adults. It is a mild self limiting disease of world wide distribution, however can be of serious consequences if contracted by a pregnant woman. Women contracting rubella infection during the first trimester of pregnancy may lead to miscarriage or stillborn baby. If the baby survives it can lead to Congenital Rubella Syndrome (CRS) in newly born with severe heart disorders, blindness, deafness, mental retardation or other life threatening disorders. With estimated $\sim 30$ million annual pregnancies, the assumed CRS load is $\sim 29000$ cases per year ${ }^{(3)}$.

Mumps is caused by an RNA virus of family Paramyxoviridae and genus Rubula. Mumps is an acute infectious disease. Unilateral or bilateral parotid gland enlargement occurs 24 hours after initial symptoms. Typical acute parotitis occurs in only about $30-40 \%$ of cases, while $15-20 \%$ of infections are completely asymptomatic and up to $50 \%$ of infections are associated with nonspecific or primary respiratory symptoms. Although disease is generally mild and self-limited but occasional complications may ensue; like aseptic meningitis, encephalitis, permanent deafness, orchitis and pancreatitis ${ }^{(4)}$.
Pregnant women with mumps have increased risk of embryonic and fetal death as well as spontaneous abortion but do not seem to have any relation to fetal congenital anomalies ${ }^{(5)}$. But one study revealed that like rubella, mumps in pregnancy can also give rise to fetal damage in the form of aqueductal stenosis leading to congenital hydrocephalu. ${ }^{(6)}$.

The burden of mumps remains high (100-1000 cases/100000 population) in countries which do not offer routine mumps vaccination, with epidemic peaks every $2-5$ years ${ }^{(4,7)}$. Of late, there has been resurgence of mumps even in countries using mumps vaccine in their National Immunization Programs (NIPs) $)^{(8,9,10)}$.

Measles virus is an RNA virus belonging to family Paramyxoviridae and genus Morbillivirus. The prodromal signs and symptoms include malaise, fever, conjuctival injection, cough and nasal discharge and rash appears after 3-4 days of prodromal illness. A day before the rash, Koplik's spots develop on the buccal mucosa and occasionally on the conjunctiva and intestinal mucosa. Complications are common and may be quite serious, many develop neurological sequelae, subacute sclerosing panencephalitis may also occur late. It is a leading cause of death among young children in many developing countries, accounting for $4 \%$ mortality in children aged less than 4 years. Prevalence of measles virus infection is approximately $98 \%$ in developing countries ${ }^{(11)}$. If measles occurs during the late stages of pregnancy, maternal and fetal morbidity are increased. Pregnant women have higher risk of miscarriage, severe respiratory distress, pneumonitis, hospital admission and death. Fetal death, prematurity and subacute sclerosing panencephalitis are seen more often in infants of these women ${ }^{(12)}$. The World Health Organization estimated in 2005 that there were $30-40$ million measles cases and 530,000 deaths annually worldwide. Measles is the fifth leading global cause of mortality among children under 5 years of age and measles deaths occur disproportionately in Africa and Southeast Asia ${ }^{(13)}$

Varicella zoster virus belongs to subfamily Alpha 
herpesvirinae and genus varicellovirus. It's official name is herpes virus type 3 which causes chickenpox. Chickenpox in pregnancy can be dangerous for both mother and baby. It is characterised by fever, malaise and pruritic rash that develops into crops of maculopapules which become vesicular and crust over before healing ${ }^{(14)}$.

In pregnant women chickenpox is associated with greater morbidity due to pneumonia, hepatitis and encephalitis. It may also cause fetal varicella syndrome (FVS) or congenital varicella syndrome in the newborn. FVS is characterised by one or more of the following: Skin scarring in a dermatomal distribution, microphthalmia, chorioretinitis, cataracts, hypoplasia of the limbs, dysfunction of bowel and bladder sphincters and neurological abnormalities eg microcephaly, cortical atrophy, intellectual disability ${ }^{(15)}$. Despite improvements in clinical care, varicella may be complicated by pneumonia in up to $28 \%$ of pregnant women and this remains associated with a risk of mortality. In a recent report of 198 cases of varicella in pregnancy, 16 deaths were reported, all in the group complicated by pneumonia ${ }^{(16)}$. Maternal varicella occurring five days before to two days after delivery is associated with severe neonatal varicella in $17 \%$ to $30 \%$ of infants and a case fatality rate as high as $31 \%{ }^{(17)}$.

Almost all studies on seroprevalence of rubella amongst Indian female revealed that $10-30 \%$ of adolescent girls and $12-30 \%$ of women in reproductive age group are susceptible ${ }^{(18,19)}$. Three studies revealed status of susceptibility in young children and adolescent against mumps and found susceptibility rate ranging from $32 \%$ to $80 \%$ in different age group ${ }^{(20-22)}$. The estimated global measles death in 2007 was 197,000 of which India contributed about $67 \%$. Majority of these deaths occur in states like UP, Bihar, Rajasthan, MP, Jharkhand and the North Eastern States ${ }^{(23)}$. India reported 18,668 cases of measles in 2012, recording the second highest number in sub-Saharan Africa and the South East Asian region, according to WHO statistics ${ }^{(24)}$. Among vaccine preventable diseases, measles is the leading cause of death with an estimated 450 deaths each day world wide ${ }^{(25)}$. Average incidence of varicella in pregnant women is $1-3$ per 1000 pregnancies. The incidence of pneumonia complicating varicella in pregnancy has been quoted at $10-14 \%{ }^{(26)}$.

Pregnant women are in contact with health care provider so it is best time to identify susceptible women and provide immunization postpartum. Moreover the antenatal women are the healthy population representing the community. Study of the immune status in antenatal mothers would be an indication of immune status in female population of the similar age group.

\section{AIMS AND OBJECTIVES}

To identify presence of IgG antibodies for Rubella virus,Mumps virus Measles virus and Voricella zoster virus in pregnant women attending Gangori Bazar Hospital, Jaipur.

\section{MATERIAL AND METHODS}

Study Area and Site: This study was conducted in ICMR Grade 1 Virology Lab , Advance Research laboratory, Department of Microbiology \& Immunology of SMS Medical College, Jaipur.

Study Design: This was a cross sectional and descriptive type of study.

Study Period: This was completed in period of April 2014-June 2015.

Study Population: Pregnant women attending ANC clinic in Gangori Bazaar Hospital,Jaipur.

Sample Size : Available data from India suggest that 12-30\% of the women in reproductive age group are susceptible to rubella. However, calculated sample size was 277 ( $\alpha$ error $5 \%$ and power of study (1- $\beta$ ) is $80 \%$ and confidence interval $95 \%$ ) from the ANC attendees. It was assumed that sero-prevalance would be more for mumps, measles and varicella to rubella and the same sample size would suffice.

Inclusion Criteria: Healthy ANC attendees.

Exclusion Criteria: Ill subjects, those with bad obstetric history, history of diabetes, history of hypertension, immunecompromised patient were excluded.

Sample Collection: Informed consent was taken for taking blood samples and the use of personal data being collected using a specific form, $4-5 \mathrm{ml}$ blood samples were collected from pregnant women attending antenatal clinics after filling the questionnaire which was specifically designed for study. Separated serum specimen in aliquots were stored at $-20 \mathrm{c}$ until tested. Each specimen was given an unique identification number and a companion clinical proforma.

The questionnaire concerned socio-demographic data as name, husband name, age, residence, educational qualification, information about MMR /MR vaccination history and gravidity of women.

\section{Ethical consideration}

The implications of rubella, mumps, measles and varicella infection was clearly explained to the study participants for them to understand the disease under investigation and type of specimens to be collected. It was explained that congenital rubella syndrome, congenital varicella syndrome, mumps and measles infections affect individuals differently and there was no treatment but management was based on individual complications. Patients were given clear explanation of the disease and why it was mandatory for a blood sample to be collected so as to confirm virus infection as it was a notifiable disease.

\section{Data analysis:}

Data was summarized and classified in MS excel worksheet in the form of master chart. Data was analyzed and interfered with use of appropriate statistics.

\section{Method}

The concentration of human IgG antibodies for rubella, mumps, measles and varicella was determined using commercial ELISA test according to manufacturer's instructions. The calculation of results obtained by qualitative assay considered the optical density of each negative, positive and cut off control.

\section{Interpretation of results}

For mumps measles and varicella(calbiotech ELISA kit)

Antibody Index Interpretation

- $\quad<0.9$ No detectable antibody

- 0.9-1.1 Borderline positive

- >1.1 Detectable antibody

For rubella (Diapro ELISA kit)

Samples with a concentration lower than $10 \mathrm{WHO} \mathrm{IU} / \mathrm{ml}$ were considered negative for anti rubella virus IgG antibody by most of the international medical literature. Samples with a concentration higher than $10 \mathrm{WHO} \mathrm{IU} / \mathrm{ml}$ were considered positive for anti rubella virus IgG antibody.

\section{OBSERVATIONS AND RESULTS}

Total 277 pregnant women attending antenatal clinic in the reproductive age group (15-45year) were included in our study. The demographic data included thier name, age, residence, education history of MMR vaccine and gravidity.

Majority of women 262/277(94.6\%) did not know about their 
immunization status both combined vaccine or any of the three single vaccines in the past. Only $15 / 277$ (5.4\%) women knew their immunization status about combined MMR vaccination.

Table-l Susceptibility of pregnant women to different viruses

\begin{tabular}{|l|c|c|}
\hline Name of viruses & $\begin{array}{c}\text { Number of susceptible } \\
\text { women }\end{array}$ & Percentage \\
\hline Rubella & 21 & $7.6 \%$ \\
\hline Mumps & 49 & $17.6 \%$ \\
\hline Measles & 20 & $7.2 \%$ \\
\hline Varicella & 54 & $19.5 \%$ \\
\hline
\end{tabular}

Among the 277 pregnant women highest susceptibility was found against varicella (19.5\%).

(A) Residence

Table-2 Showing susceptibility of participants to viruses in relation to residence

\begin{tabular}{|c|c|c|c|c|}
\hline Residence & Rubella & Mumps & Measles & Varicella \\
\hline Urban(193) & $\begin{array}{c}12 \\
(6.2 \%)\end{array}$ & $\begin{array}{c}33 \\
(17.1 \%)\end{array}$ & $\begin{array}{c}14 \\
(7.2 \%)\end{array}$ & $\begin{array}{c}39 \\
(20.2 \%)\end{array}$ \\
\hline Rural(84) & 9 & 16 & 6 & 15 \\
& $(10.7 \%)$ & $(19 \%)$ & $(7.1 \%)$ & $(17.8 \%)$ \\
\hline P value & 0.292 & 0.74 & 0.817 & 0.787 \\
\hline
\end{tabular}

( $\mathrm{P}>0.05$ not significant for rubella, mumps, measles and varicella )

Susceptibility rates for rubella and mumps were higher in rural population as compares to urban while for varicella urban population was more susceptible. But it was not statically significant.

\section{(B) Age groups}

Table-7 Showing susceptibility to different viruses in relation to age groups

\begin{tabular}{|c|c|c|c|c|}
\hline $\begin{array}{c}\text { Age groups } \\
\text { (in years) }\end{array}$ & Rubella & Mumps & Measles & Varicella \\
\hline $15-19(13)$ & $\begin{array}{c}0 \\
(0 \%)\end{array}$ & $\begin{array}{c}1 \\
(7.7 \%)\end{array}$ & $\begin{array}{c}0 \\
(0 \%)\end{array}$ & $\begin{array}{c}5 \\
(38.4 \%)\end{array}$ \\
\hline $20-24(152)$ & 9 & 32 & 16 & 29 \\
$(5.9 \%)$ & $(21.1 \%)$ & $(13.2 \%)$ & $(19.1 \%)$ \\
\hline $25-29(83)$ & 8 & 13 & 2 & 15 \\
& $(9.6 \%)$ & $(15.7 \%)$ & $(2.4 \%)$ & $(18.1 \%)$ \\
\hline$\geq 30(29)$ & 4 & 3 & 2 & 5 \\
& $(13.7 \%)$ & $(10.3 \%)$ & $(6.8 \%)$ & $(17.2 \%)$ \\
\hline P value & 0.388 & 0.382 & 0.111 & 0.445 \\
\hline
\end{tabular}

( $\mathrm{P}>0.05$ not significant for rubella, mumps, measles and varicella)

No correlation was found between age of patient and susceptibility status to viruses, youngest age group was most susceptible to varicella and oldest group to rubella.

\section{(C) Education}

Table-8 Showing susceptibility of partcipants to different viruses in relation to their education

\begin{tabular}{|l|c|c|c|c|}
\hline \multicolumn{1}{|c|}{ Education(n) } & Rubella & Mumps & Measles & Varicella \\
\hline Postgraduation(17) & 1 & 2 & 0 & 2 \\
& $(5.9 \%)$ & $(11.8 \%)$ & $(0 \%)$ & $(11.7 \%)$ \\
\hline Graduation(24) & 1 & 5 & 1 & 5 \\
& $(4.2 \%)$ & $(20.8 \%)$ & $(4.2 \%)$ & $20.8 \%)$ \\
\hline Higher secondary(29) & 2 & 1 & 1 & 10 \\
& $(6.8 \%)$ & $(3.4 \%)$ & $(3.4 \%)$ & $(34.5 \%)$ \\
\hline Secondary(52) & 7 & 11 & 4 & 6 \\
& $(13.4 \%)$ & $(21.1 \%)$ & $(7.6 \%)$ & $(11.5 \%)$ \\
\hline Primary(87) & 5 & 15 & 7 & 16 \\
& $(5.7 \%)$ & $(17.2 \%)$ & $(8 \%)$ & $(18.3 \%)$ \\
\hline
\end{tabular}

\begin{tabular}{|l|c|c|c|c|}
\hline Illiterate(68) & 5 & 15 & 7 & 15 \\
& $(7.3 \%)$ & $(22.1 \%)$ & $(10.3 \%)$ & $(22.1 \%)$ \\
\hline P value & 0.740 & 0.348 & 0.769 & 0.220 \\
\hline
\end{tabular}

( $P>0.05$ not significant for rubella, mumps, measles and varicella)

No correlation could be observed in susceptibility to different viruses and their education status.

\section{Gravidity}

Table-9 Showing status of susceptibility to viruses in relation to gravidity

\begin{tabular}{|c|c|c|c|c|}
\hline Gravidity(n) & Rubella & Mumps & Measles & Varicella \\
\hline $\begin{array}{c}\text { Primigravida } \\
\text { (125) }\end{array}$ & $\begin{array}{c}12 \\
(9.6 \%)\end{array}$ & $\begin{array}{c}20 \\
(16 \%)\end{array}$ & $\begin{array}{c}6 \\
(4.8 \%)\end{array}$ & $\begin{array}{c}27 \\
(21.6 \%)\end{array}$ \\
\hline $\begin{array}{c}\text { Multigravida } \\
\text { (152) }\end{array}$ & 9 & 29 & 14 & 27 \\
& $(5.9 \%)$ & $(19.1 \%)$ & $(9.2 \%)$ & $(17.7 \%)$ \\
\hline P value & 0.356 & 0.610 & 0.239 & 0.516 \\
\hline
\end{tabular}

( $P>0.05$ not significant for rubella, mumps, measles and varicella)

Primigravida were more susceptible to rubella and varicella while multigravida weremore susceptible to mumps and measles. But it was not stastically significant.

\section{DISCUSSION}

The present study was done to assess immune status of pregnant women for rubella, mumps, measles and varicella attending a tertiary care center in Jaipur.

In our study susceptibility for rubella, mumps, measles and varicella was found to be $7.6 \%, 17.6 \%, 7.9 \%$ and $19.4 \%$ respectively.

In older Indian studies done during 1972-1982 the range of susceptibility for rubella were $12.7 \%$ to $32.5 \%{ }^{(27-30)}$. While newer studies report lower susceptibility, $5.4 \%$ at Vellore by Black et $\mathrm{al}^{(31)}, 5.1 \%$ at Hyderabad by Bhaskaram et $\mathrm{al}^{(32)}$. Susceptibility rates were similar to our study in foreign countries also, $9.4 \%$ at U.S.by Hass et al ${ }^{(33)}, 9.4 \% \%$ from Saudi arabia by Sharifa et $\mathrm{al}^{(34)}, 4 \%$ at Iran by Behman et $a l^{(35)}, 3.4 \%$ at Nigeria by Obijimi et $\mathrm{l}^{(36)}$ and $5 \%$ at Spain by Plans et al ${ }^{(37)}$.

However higher susceptibility rates were reported from various studies from India than our study. Three studies from Delhi reported wide variation in susceptibility $12.8 \%$ by Ekta et $\mathrm{cl}^{(38)}, 14.6 \%$ Gandhoke et $\mathrm{cl}^{(39)}, 21 \%$ by Deka et $\mathrm{al}{ }^{(40)}, 46 \%$ by Khare et $\mathrm{al}^{(41)}$ and $24 \%$ by Rustugi ${ }^{(42)}$. Padmaja et al ${ }^{(43)}$ from Kerala reported very high susceptibility of $37.3 \%$ and Thapliyal et al ${ }^{(44)}$ from Haldwani $33.33 \%$, a study from Karnataka done in Health science students susceptibility was $16.6 \%{ }^{(22)}, 15.3 \%$ by $\operatorname{Singh}^{(45)}$ from Chandigarh and $11.6 \%$ by Jain et al in Lucknow ${ }^{(46)}$. Even foreign studies reported high susceptibility, $22.1 \%$ from Italy ${ }^{(47)}$ and $12.7 \%$ by Fadwa et al from Saudi Arabia ${ }^{(48)}$. Across the globe there is a considerable variation in susceptibility of rubella in childbearing age. European women have lower susceptibility $(6.85 \%)$ as compared to women of Africa (13.3\%)and Asian origin $(21.6 \%)^{(49)}$.

For mumps and measles no data is available on their susceptibility in pregnant women in India, one study done in health students by Kumar et al ${ }^{(22)}$ in Karnataka, susceptibility for mumps and measles were $32 \%$ and $9.5 \%$ respectively and by Afgah et al in Iran ${ }^{(50)}$ in health and dental student susceptibility were $24 \%$ and $48 \%$. Another study conducted by Hass Dm in United state ${ }^{(33)}$ in pregnant women reported susceptibility for mumps and measles to be $16.3 \%$ and $16.5 \%$ respectively and by Plans P et al from Spain ${ }^{(37)}$ it was $19 \%$ and $11 \%$ respectively.

Similarly data on varicella in pregnant women is not 
available, few studies done on students reported varicella susceptibility to be $25.8 \%$ by G Arun kumar et al from Karnataka ${ }^{(22)}, 15 \%$ by Afgah et al at Iran ${ }^{(50)}, 3.7 \%$ by $\mathrm{S}$ kumakara et al at Japan ${ }^{(51)}$.

In our study susceptibility in rural area was higher for rubella and mumps than urban. Susceptibility for rubella, mumps, measles and varicella in the participants which belonged to urban area were $6.2 \%, 17.1 \%, 7.2 \%$ and $20.2 \%$ respectively and those belonging to rural area were $10.7 \%, 19 \%, 7.1 \%$ and $17.8 \%$.

A study conducted by Seth et al at Delhi observed the susceptibility for rubella to be $20.5 \%$ for urban population and $30 \%$ for rural population ${ }^{(52)}$.

However there is no data available which show the susceptibility for mumps, measles and varicella in respect to urban and rural population.

In our study on the basis of their age groups susceptibility for rubella virus increased with age, age group $15-19$ year $(0 \%)$, for $20-24$ year $(5.9 \%)$, for $25-29$ year $(9.6 \%)$ and over the age of 30 year (13.7\%).

Similar results were seen in a study done by Gupta et $a{ }^{(38)}$ at Delhi, their susceptibility in age group $15-19$ year was $7.5 \%$ and in $25-30$ year the susceptibility was $13 \%$. The possible explanation was more exposure of younger age group to rubella and other explanation was that higher immunity in the younger age group could also be due to persistence of immune response to MMR vaccination in childhood and waning of immunity with age.

Other studies showing similar results were by Kumakura et al in Japan ${ }^{(51)}$ who reported susceptibility for rubella increase with increasing age.

For mumps highest susceptibility in age group 20-24 year was $21.7 \%$ followed by $25-29$ year ( $15.7 \%$ ) then over 30 year $(10.3 \%)$ and lowest susceptibility for age group $15-19$ year was $7.7 \%$. A study conducted by Elisa langiano et $\alpha{ }^{(52)}$ in Italy showed that susceptibility for mumps was higher in age group 21-25 year and another study done by S. Kumakura ${ }^{(51)}$ in Japan in HCW susceptibility was high in under 29 year age group(11\%), compared to $30-39$ year $(7.4 \%)$ and for $40-49$ year $(5 \%)$.

In our study the result for measles was highest susceptibility in age group $20-24$ year was $13.2 \%$ followed by age group over 30 year $(6.8 \%)$ then age group $25-29$ year $(2.4 \%)$ and lowest susceptibility for age group 15-19 year was 0\%.A study conducted by Langiano in Italy ${ }^{(52)}$ showed that susceptibility for measles was higher in age group 21-25 year and over 31 year age groups. Another study done by Kumakura ${ }^{(51)}$ in Japan in HCW susceptibility was higher in under 29 year age group ( $14.3 \%)$, compared to $30-39$ year $(7.8 \%)$ and for $40-49$ year age group (0.8\%)

In our study for varicella, highest susceptibility was seen for the age group $15-19$ year (38.4\%) followed by the age group $20-24$ year $(19.1 \%)$ and almost similar susceptibility in age group $25-29$ year (18.1\%) and over 30 year (17.2\%). A study conducted by Kumakura in Japan ${ }^{(51)}$ showed no age related significant difference in susceptibility for varicella. A study done by G.Gabutti ${ }^{(53)}$ in Italy in reproductive age group susceptibility in age group $15-19$ year was $17.2 \%$ and for $20-39$ year was $9.2 \%$.

Studies from Spain ${ }^{(54)}$ in the period of 1996 -2003 showed that susceptibility for varicella in the $15-24$ year age group was $6 \%$ followed by age group $25-29$ year $(5 \%)$ and for age group 30 49 year susceptibility was $<5 \%$.
Several surveys investigated the rubella, mumps, measles and varicella susceptibility in different countries in similar setting and age specific profile of these viruses have wide variation. In places where the vaccine has been given in childhood, it is observed that immunity decreases with age while in others the pattern is variable depending on occurrence of natural infection and immunity achieved subsequent to it. However as the number of studies have documented decrease in immunity over the years, administration of booster dose at the time of the entry in health care system for health care worker and before marriage may be advocated for young women.

In our study no correlation was found in susceptibility to rubella, mumps, measles and varicella viruses and the education level of the pregnant women enrolled in the study. Other studies done by Maryam et al in Iran ${ }^{(55)}$ and Obijimi et al from Nigeria ${ }^{(36)}$ also observed no effect of education on susceptibility .

Though no correlation of susceptibility of different viruses with education was observed but to increase awareness it would be advisable to educate the high secondary students about the vaccine preventable viruses and need for immunization. Moreover it is important to carry out information, education and communication (IEC) activities for general public such that they can ask for immunization and help in prevention and control of infections by these viruses.

In our study susceptibility for rubella and varicella were higher in primigravida $(9.6 \%, 21.6 \%)$ compared to multigravida $(5.9 \%, 17.7 \%)$ women respectively. Susceptibility for mumps and measles were higher in multigravida (19.1\%,9.2\%) compared to primigravida (16\%,4.8\%) but were not significant statistically. A study done by Amita Jain et al at Lucknow also observed no relation of parity to their susceptibility to different viruses ${ }^{(46)}$.

A study was conducted by Mahmoudi and his colleages in Mashad during years 2001-2004 for evaluating immune status against rubella of women before and after vaccination programme. They evaluated 1698 women before and 354 after vaccination. Immunity level achieved before vaccination were $67.19 \%$ and $77.4 \%$ post vaccination ${ }^{(56)}$.

Choice of vaccines in National Immunization Schedule warrants careful decision and periodic reviews. In 1978, India adopted the Expanded Programme on Immunization (EPI) promoted by World Health Organization (WHO). In 1985, EPI was renamed as Universal Immunization Program (UIP). Four Union Territories (Delhi, Goa, Pudduchury and Sikkim) are already using MMR in their Universal Immunization Programme (UIP). The coverage of MMR vaccine has been reported as $42 \%, 30 \%$ and $5 \%$ from Delhi, Chandigarh and Goa, respectively ${ }^{(57)}$. Kerala became the latest entrant to start universal MMR vaccination in the state from 2014. By 2012, 132 of 194 WHO member states had also introduced rubella containing vaccine (RCV) in their National immunization programs (NIP), either as MR or MMR. Of these, 117 have RCV included in both routinely administered doses of measlescontaining vaccine ${ }^{(58)}$.

Nearly $45 \%$ females in the reproductive age group in India are susceptible to infections during pregnancy ${ }^{(59)}$. For control, the target age groups should be from 9 months to 15 years (following introduction in NIP). Further decision to expand is to be guided by the epidemiology of the disease (age distribution, sero-prevalence data, age-specific fertility rates, susceptibility data of women of child bearing age and maternal age distribution of CRS. For elimination, we must target all the above age groups along with expansion of target age of coverage beyond 15 years. They should include special 
immunization activities targeting adults (up to 40 years of age). Further age groups for inclusion in target age for these activities will depend on sero-epidemiology data. Here, both the sexes, must be included for vaccination ${ }^{(60)}$.

Pre-conceptional screening and immunization of pregnant women are not yet adequate in India. Its suggested that immunization should be part of preconception care. No specific programmes or initiatives have been endorsed so far by the WHO to promote varicella immunisation or prevention of congenital varicella ${ }^{(61)}$.

It is important to educate women of child bearing age about the importance of vaccination against some of these diseases, as many of these congenital infections are preventable. Most of this education should be targeted toward teenaged girls, as many young women will not seek medical care outside their pediatrician until they are already pregnant.

Educating the pregnant patient to avoid contact with persons with viral infections and frequent hand washing when handling children can prevent infection. If exposure does occur, the patient should seek immediate assistance for postexposure prophylaxis with varicella immunoglobulin ${ }^{(62)}$.

There is an urgent need to start MMR in the Universal immunization programme so as to reduce the disease burden. However states which have the ability to achieve and sustain routine immunization coverage of $>80 \%$ should be considered first and other states to be encouraged to increase vaccination coverage. This would also provide a second opportunity for measles vaccination.

Moreover large scale well planned studies on CRS and CVS in India should also be carried out to know exact disease burden and areas where extra care is needed.

\section{CONCLUSION}

In our study we found that very high number of pregnant women were susceptible to varicella and lesser for rubella, mumps and measles. These viruses increase mortality and morbidity among the pregnant women and their unborn babies. In India MMR and varicella vaccine are being given as part of immunization programme in many states like Delhi, Goa, Puducherry, Sikkim and recently in Kerala but not in all states of the country. Minimum $80 \%$ coverage is required for control of these viruses which will not allow virus to circulate freely and infect women of child bearing age. In India the coverage of MMR and varicella vaccine has been reported to be very low. For control and elimination of these viruses. We should include special immunization activities targeting adults, adolescent girls and women of childbearing age.

\section{REFERENCES}

1. Robinson JL, Lee BE, Preiksaitis JK, Plitt S, Tipples GA. Prevention of Congenital Rubella Syndrome-What Makes Sense in 2006? Epidemiol Rev. 2006; 28:81-7.

2. Domínguez PP, Costa J, Torner N, Cardenosa N, Batalla N, Plasencia A, et al. Seroprevalence of measles, rubella, and mumps antibodies in Catalonia, Spain: results of a cross-sectional study. Eur J Clin Microbiol Infect Dis. 2006; 25(5): 310.

3. Gershon AA, Mandel GL, Bennet JE, Dolin R. Mandell, Douglas and Benner's principles and practice of infection disease .5th ed.2000;1708-1714.

4. Galazka A, Robertson S, Kraigher A. Mumps and mumps vaccine: Global review.Bull WHO. 1999; 77:3-14

5. CDC Update: Mumps Outbreak- New York and New Jersey, Morbidity and Mortality Weekly Report. 2009-2010; 59 (5): 125-129, 201.

6. WHO Position Paper, Mumps Virus Vaccines. Wkly Epidemiol Rec. 2007; 82:49-60.

7. World Health Organization. Position paper.Mumps virus vaccines. Wkly Epidemiol Rec. 2007; 7: 51-60.

8. Atrasheuskaya AV, Kulak MV, Rubin S, Ignatyev GM. Mumps vaccine investigation in Novosibirsk, Russia, 2002-2004. Clin Microbiol Infect. 2007;13: 670-676.

9. Centers for Disease Control and Prevention (CDC). Update: Mumps Outbreak - New York and New Jersey, June 2009- January 2010. MMWR Morb Mortal Wkly Rep. 2010; 59:125-129.

10. Kutty PK, McLean HQ, Lawler J, Schulte C, Hudson JM, Blog D, et al. Risk factors for transmission of mumps in a highly vaccinated population in Orange County, NY, 2009-2010. Pediatr Infect Dis J. 2014; 33: 121-125.

11. Alavian SM, Fallahian F, Lankarani KB. The changing epidemiology of viral hepatitis B in Iran. J Gastrointestin Liver Dis. 2007;16(4):403. 3. Blume S Tump J. Evidence and policymaking: The introduction of MMR vaccine in the Netherlands. Soc Sci Med. 2010; 71(6):1049-55.

12 Anselem O, Tsatsaris V, Lopez E, Krivine A, Le Ray C, et al. (2011) [Measles and pregnancy]. Presse Med. 40(11): 1001-1007.

13. Geo.f.Brooks, Karen C. Carroll, Janet S. Butel, StephenA.Moris. Jawetz, Melniks \& Adelberg's Medical Microbiology. Mc Graw Hill. edi 24th:562.

14. Geo.f.Broo ks, Karen C. Carroll, Janet S. Butel, StephenA.Moris. Jawetz Melniks \& Adelberg's Medical Microbiology. Mc Graw Hill. edi 24th:437

15. Willey $\mathrm{H}$. Antenatal infections and their consequences.2014; page 2 .

16. Gershon AA. Chicken pox, measles and mumps. In: Remington JS, Klein JO eds. Infectious diseases of the fetus and newborn infant. Philadelphia: WB Saunders; 2001: 683 .

17. Denicola LK, Hanshaw JB. Congenital and neonatal varicella. J Pediatr 1979;94(1):175-176.

18. Gomber S, Arora SK, Das S, Ramachandran VG.Immune response to second dose of MMR vaccine in Indian children. Indian J Med Res. 2011;134:302-6.

19. Raut SK, Kulkarni PS, Phadke MA, Jadhav SS, Kapre SV, Dhere RM, et al. Persistence of antibodies induced by measles-mumps-rubella vaccine in children in India. Clin Vaccine Immunol. 2007; 14:1370-1.

20. Chakravarti A, Yadav S, Berry N, Rastogi A, Mathur MD. Evaluation of serological status of rubella and mumps in children below five years. Indian J Med Res. 1999; 110:1-3.

21. Yadav S, Thukral R, Chakravarti A. Comparative evaluation of measles, mumps and rubella vaccine at 9 \& 15 months of age. Indian J Med Res. 2003;118:183-186

22. Arun kumar G, Vandana KE, Sathia kumar N. Prevalence of measles, mumps, rubella, varicella susceptibility among health science students in a University in India. Am J Ind Med. 2013;56:58-64.

23. Meeting of the expert group on Measles and MMR. ICMR Hqs. 2010.

24. Status Report on Progress Towards Measles and Rubella Elimination. SAGE Working Group on Measles and Rubella .2013.

25. Esteghamati A, Gouya MM, Zahraei SM, Dadras MN, Rashidi A, et al Progress in measles and rubella elimination in Iran. Pediatr Infect Dis J.2007;26(12): 1137-41.)

26. Chickenpox in pregnancy. Royal College of Obstetricians and Gynaecologists .2007.

27. Chaturvedi UC, Tripathi BN, Mathur A, Singh UK, Mehrotra RM. Role of rubella in congenital malformations in India. J Hyg (Lond). 1976;76:33-40.

28. Pal SR, Chitkara NL, Broor S, Murthy JG, Choudhury S, Devi PK. Serological investigation of rubella virus infection in and around Chandigarh-a preliminary communication. Indian J Med Res. 1974:62:240-5.

29. Shanmugam J, Raveendranath M, Nair VR. Seroprevalence of rubella and cytomegalovirus (CMV) infection in pregnant women from Kerala State. J Indian Assoc Commun Dis. 1982;5:58-63.

30. Mathur A, Tripathi R, Chaturvedi UC, Mehra P. Congenital rubella following inapparent rubella infection. Indian J Med Res. 1982;75:469-73.

31. Black FL, Berman LL, Borgoño JM, Capper RA, Carvalho AA, Collins C, et al. Geographic variation in infant loss of maternal measles antibody and in prevalence of rubella antibody. Am J Epidemiol. 1986;124:442-52

32. Bhaskaram P, Ramalakshmi BA, Raju LA, Raman L. Need for protection against rubella in India. Indian J Pediatr. 1991;58:811-4

33. Hass DM, Flowers CA, Congdon CL..Rubella, rubeola, and mumps in pregnant women: susceptibilities and strategies for testing and vaccinating 2005;106(2):295-300

34. Sharifa A. Alsibiani. Rubella Immunity among Pregnant Women in Jeddah Western Region of Saudi Arabia. Obstetrics and Gynecology International. 2014;659-838.

35. Honarvar B, Moghadami M, Moattari A, Emami A, Odoomi N BagheriLankarani K. Seroprevalence of anti-rubella and anti-measles IgG antibodies in pregnant women in Shiraz, Biomed 2014; 2(1): 6-9.

36. Obijimi,T.O.et al. Prevalence of Rubella Virus specific immunoglobulin-G and $-\mathrm{M}$ in pregnant women attending two tertiary hospitals in southwestern Nigeria. ISBN.2013;14(3):1595

37. Plans P, de Ory F, Campins M, Álvarez E, Payà T, Guisasola E et al .Prevalence of anti-rubella, anti-measles and anti-mumps IgG antibodies in neonate and pregnant women in Catalonia (Spain) .Eur j clin microbial dis.2015; 34 (6):1161-71.

38. Gupta E, Dar L, Broor S .Seroprevalence of rubella in pregnant women in Delhi, India . Indian J Med Res. 2006; 123: 833-835.

39. Gandhoke I, Aggarwal R, Lal S, Khare S. Seroprevalence and incidence of rubella in and around Delhi (1988-2002).Indian J Med Microbiol 2005;23:164167.

40 Deka D, Rustgi R, Singh S, Roy KK, Malhotra N. Diagnosis of acute rubella infection during pregnancy. Journal of Obstetrics and Gynaecology of India. 2006;56:44-46

41. Khare S, Banerjee K, Padubidri V, Rai A, Kumari S, Kumari S. Lowered immunity status of rubella virus infection in pregnant women. J Commun Dis. 1987; 19:391-5

42. Rustgi R, Deka D, Sarman S. Rubella serology in Indian adolescent girls and its relation to socio-economic status. Journal of Obstetrics and Gynaecology of India. 2005;55:167-9.

43. Padmaja M, Radhakrishna PM, Varghese SJ.Seroprevalence of immunity to rubella in pregnant women.Natl Med J India. 2010;23: 248-9.

44. Thapliyal N, Shukla PK, Kumar B, Upadhyay S, Jain G. TORCH infection in women with bad obstetric history - a pilot study in Kumaon region. Indian J Pathol Microbiol. 2005:48:551-553.

45. Singh M, Chatterjee S, Singh R, Goyal K, Ratho R .Rubella seronegativity among health care workers in a tertiary care north Indian hospital, Implications for immunization policy. IJPM.2013;56 (2):148-150.

46. Gupta A, Jain P and Jain A. Sero-prevalence of Rubella Virus Antibodies in Pregnant Women in the Vicinity of Lucknow, Uttar Pradesh. Archives of medicine.2015. 
47 Langiano E, Ferrara M, Lanni L, Atrei P, Martellucci G, De Vito E.Rubella seroprevalence in childbearing age women: a cross sectional study in the province of Frosinone, Central Southern Italy .JPH.2009; 6(3).

48. Fadwaa Al-Sheref, Osama H. Jefrri and Zahira M.F. El-Sayed.Seroprevalence of Rubella among Pregnant Women and Young Females .Egyptian Journal of Medical Microbiology, 2010;(1).

49. Lever AML, Ross MGR, Baboonian C, Griffiths PD. Immunity to rubella among women of childbearing age. Br J ObstetGynecoll 1987; 94 : 208-212

50. Moattari A. Evalution of Measles, Rubella, Mumps, Hepatitis B and varicella zoster antibodies in medical and dental students in shiraz, iran. biomed. 2014;2(1):6-9.

51. S. Kumakura, H. Shibata, KOnoda, N. Nishimura, C. Matsuda, and MHiros Seroprevalence survey on Measles, Mumps, Rubella and Varicella antibodies in healthcare workers in Japan ,sex,age, occupation related difference and various efficiency Epidol.infect 2014;142:12-19.

52. Seth P, Balaya S, Mohapatra LN. Sero-epidemiological study of rubella infection in female subjects of Delhi and its surrounding villages. Indian J Med Res. 1971;59:190-4.

53. Gabutti G, Penna C, Rossi M, Salmaso S, Rota MC, Bella A, Crovari C.The serological study group seroepidemiology of varicella in Italy. Epidemiol Infect. 2001;126:433-440.

54. Plans P, Costa J, Espuñes J, Plasència A, Salleras A. Prevalence of varicellazoster antibodies in pregnant women in Catalonia (Spain). Rationale for varicella vaccination of women of childbearing age. BJOG. 2007;114(9):11221127

55. Razavi M, Khazaei HA, Dehghan J and Naghibzadeh N.Assessment of IgG serum level to Rubella disease in women of childbearing age in 2012 at Zahedan city and its relation to some demographic factors. Scholars Research Library .2014;5 (5):93-98.

56. 107. Mahmoud M, Ehsan V.Journal of Mashhad University of Medical Sciences. Summer 1386, Year 50; 96:177-186.

57. Background material for NTAGI Standing Technical Sub- Committee (STSC) Meeting on "Potential Strategies for the Control of Rubella and CRS Burden in India." February 26, 2014.

58. Indian Council of Medical Research, New Delhi. Status Report on Progress towards Measles and Rubella Elimination. SAGE Working Group on Measles and Rubella.l 7 October 2013 . Available from: http://www.who.int/immunization/sage/meetings/2013/november/ Status Report Measles Rubella21Oct2013 FINAL.pdf.

59. Peltola $\mathrm{H}$, Heinonen $\mathrm{O}$, Valle $\mathrm{M}$, Paunio M,Virtanen $\mathrm{M}$, Karanko $\mathrm{V}$, et al. The elimination of indigenous measles, mumps and rubella from Finland by a 12 year two dose vaccination program. N Engl J Med. 1994; 331: 1397-402.

60. Yadav S, Gupta S, Kumari S. Seroprevalence of rubella in women of reproductive age. Indian J PatholMicrobiol. 1995; 38:139-42.

61. E.pandolfi,G Chiaradia, M Moncada L Rava A E Tozzi. Prevention of congenital rubella and congenital varicella in Europe. Eurosurviellance. 2009; 14(9): article5

62. Teresa Marino. Viral infection and pregnancy. Medscape Drug, Disease and Procedure.2014. 